\title{
The Determinants of the Stock Price Performance of Analyst Recommendations
}

\author{
Yaling Lin ${ }^{1}$, Liang-Chien Lee ${ }^{1}$, Tsung-Li Chi ${ }^{1}$, Chen-Chang Lo $^{1} \&$ Wai-Shen Chung ${ }^{1}$ \\ ${ }^{1}$ Department of Finance, I-Shou University, Taiwan \\ Correspondence: Yaling Lin, No. 1, Sec. 1, Syuecheng Rd., Dashu, Kaohsiung 840, Taiwan R.O.C. Tel: \\ 886-7-657-7711 ext 5719. E-mail: auswa@isu.edu.tw
}

Received: August 9, 2019

doi:10.5539/ass.v15n11p25
Accepted: September 4, 2019

Online Published: October 20, 2019

URL: https://doi.org/10.5539/ass.v15n11p25

\begin{abstract}
This study examines the cross-sectional determinants of the price reaction to analysts' recommendations disseminated through various type of media and for firms listed in Taiwan stock markets. We measure abnormal returns using the market model of event study. Based on the type of media (traditional media/social media) and the type of exchange (Taiwan Stock Exchange (TWSE)/Taipei Exchange (TPEx)), we classify the combined sample observations into four samples and run quantile regressions to investigate whether the relation will be uniform across various quantile levels. Our results show that the relation between firm characteristics and cumulative abnormal returns is not homogeneous across various quantiles of abnormal returns. Our evidence indicates that in general the relation tends to be stronger for firms at higher performance quantile levels and tends to be more pronounced for TWSE firms. The strongest relation is found for the Traditional/TWSE sample, where the abnormal returns are positively related to insider ownership and prior-period earnings, and negatively related to institutional shareholding and price-to-book ratio for firms in the highest abnormal performance quantile.
\end{abstract}

Keywords: stock performance, firm characteristics, stock recommendation, quantile regression

\section{Introduction}

Retail investors eagerly look for all kinds of information for their investment decisions with the aim of beating the market. Investment information could be disseminated through various mass media platforms. Traditionally, investors rely on expert advices from professional financial analysts via print media (e.g. newsletter, newspaper, magazine) and broadcast media (television show). With the advances in information technology and the emergence of web-based social media, retail investors now increasingly turn to opinions or user-generated contents from peer group (Chen, De, Hu, \& Hwang, 2014). Financial analysts also tap this trend to provide investment information through these on-line media outlets, which include blogs, forums, and social networking websites such as Facebook, and Twitter.

There are voluminous studies that analyze the price effect of analyst stock recommendations in U.S. stock markets. Michaely and Womack (2005) point out that the price impact of analysts' comments and recommendations may depend on the type of audience and the methods for disseminating information. Researchers collect stock recommendations released in several media formats. These include the ranking in subscription-based newsletters (e.g., Copeland \& Mayers, 1982), news story in business magazines (e.g., Desai \& Jain, 1995), news articles and recommendations in columns of newspapers (e.g., Barber \& Loeffler, 1993; Tetlock, Saar-Tsechansky, \& Macskassy, 2008), segments or shows on television stations (e.g., Engelberg, Sasseville, \& Williams, 2012; Busse \& Green, 2002), analyst forecasts in financial databases (e.g., Womack, 1996; Loh, 2010), and posts on internet social media (e.g., Antweiler \& Frank, 2004; Chen et al., 2014). There are also studies that provide evidence on Taiwan stock markets (e.g., Lin, Lin, \& Wang, 2009) for newspaper; Chiao, Lin, and Lee (2017) for TV show; Wu and Lin (2017) for mass media). In general, there are three, main research issues in these studies. The first issue is whether the levels/revisions or other contents of analyst recommendations have impacts on price and other market activities, such as trading volume. The second issue is whether investors can earn excess returns by formulating profitable trading strategies based on the recommendations. The third issue is related to what are the cross-sectional determinants of the average abnormal returns of stock recommendation. 
Many prior studies have documented the existence of an initial price impact, followed by a post-recommendation drift on the announcement of analysts' recommendations. The main purpose of this study is to examine the determinants of the price effect of analyst buy recommendations disseminated through various media platforms. Some researchers additionally examine the determinants of the abnormal returns, as Stickel (1995) point out that the average abnormal returns may obscure factors that influence the price reaction. Researchers in these studies usually conduct cross-sectional regressions of abnormal returns on the empirical variables of interest with control variables. For example, there is well-documented size effect that the price impact is larger for smaller firms, which only have infrequent information disclosure and media coverage (Stickel, 1995). Huth and Maris (1992) however find that firm size is an important factor only for negative comments.

With the abundant research on the effect of conventional media and social media on stock markets, few papers address the issue on how these two information channels differ in affecting stock performances. Yu, Duan, and Cao (2013) study the effect of social media (blog, forum, twitter) and conventional media (ten big conventional news sources from google news) on stock return and risk, using textual analysis to construct sentiment measure from mining user-generated contents (UGC) posted on these media outlets. Their findings suggest that social media, in general, has a stronger impact on stock performance than conventional media and the magnitude of the effect varies depending on the specific type of media. One limitation of their research is that what they examine is related to the overall media sentiment rather than being finance specific (e.g., stock recommendation).

There is evidence that the impact of analysts' recommendations may be different depending on the exchange of listing, due to the difference in market structure. For example, NYSE and AMEX are centralized exchanges with designated specialists as market makers and a call market trading mechanism for the opening trade and a continuous trading mechanism for subsequent transactions. NASDAQ is operated under a quote-driven and competitive computerized dealer market. Kim, Lin, and Slovin (1997) report that analysts' buy recommendations generate an average excess return of approximately $4 \%$ for NYSE and AMEX stocks and $7 \%$ for NASDAQ stocks. Chang and Chan (2008) examine the price impact of stock recommendation revisions on NYSE, AMEX and NASDAQ firms. Their results from OLS regressions show that the coefficients on the indicator variable for stock exchange listing, one for NYSE listing and zero otherwise, are significantly negative (positive) for the samples of upward (downward) revisions.

In Taiwan, securities are also traded in two types of market structure. Taiwan Stock Exchange (TWSE) is a centralized market, operated by the Taiwan Stock Exchange Corporation (TSEC). An over-the-counter (OTC) market is operated by the Gre Tai Securities Market (GTSM), which is a juristic person (foundation) partly endowed by TSEC. The listing requirements in TWSE are more stringent, with listed firms tending to be larger, older, and more established with a richer information environment. In February 2015, the GTSM changed its English name to Taipei Exchange (TPEx). There are two trading platforms for stocks in TPEx, the Mainboard for listed firms and the Emerging Stock Board (ESB) for registered-yet-unlisted public companies. TWSE uses a centralized trading system with orders matched by call auction during all trading sessions. TPEx uses a similar automated trade matching system for the trading of Mainboard listed shares, while a negotiated trading system is used for ESB stocks. As of December 31, 2017, the number of companies listed on TWSE was 907 with a market capitalization of about TWD 31.8 trillion. There were 744 companies listed on the Mainboard of TPEx with a market capitalization of some TWD 3.3 trillion. Domestic individual investors account for $59.4 \%$ of the trading value on TWSE and $80.8 \%$ on TPEx. Although these two exchanges adopt the same trading mechanism for listed stocks, they have other different features. We are therefore interested in examining whether the determinants will be different for firms listed in TWSE and TPEx.

In this study, we aim to contribute to current research in twos ways. First, with a unique data set from Taiwan stock market, we explore the impact of firm characteristics on the abnormal returns at different quantile levels, instead of the mean. Second, we examine the determinants according to the type of media, through which recommendations are disseminated, and the type of exchange where recommended firms are listed. The results in this paper show that the relation between firm characteristics and abnormal returns are not homogeneous and tend to be significant for firms at higher performance quantile levels. The effects are also more significant for TWSE firms with recommendations released through conventional media.

The rest of the paper is organized as follows. In Section 2, we review the related literature and discuss our research design. Section 3 describes our data and sample selection criteria. We present and discuss the main empirical results in Section 4. Section 5 concludes the paper.

\section{Related Studies}

Our paper is related to the literature on the role of financial analysts, especially the impact of their 
recommendations on stock market activities and the literature on the effect of media on financial markets. Michaely and Womack (2005) and Tetlock (2015) provide reviews on these two strands of literature, respectively. The extant studies provide evidences regarding whether publically available information and text-based qualitative information have informative value and provide tests on market efficiency and behavioral biases.

Many prior studies have documented that analyst stock recommendations have informative values that lead to an initial price reaction in the direction forecast (e.g., Stickel, 1995; Womack, 1996; Barber, Lehavy, McNichols, \& Trueman, 2001). Results from prior research also suggest that recommendation changes are more informative than mere levels (e.g., Barber, Lehavy, \& Trueman, 2010). While Liu, Smith, and Syed (1990) report that the impact of buy and sell recommendations seems to be symmetric, Womack (1996) document that the market reaction to buy and sell recommendation changes is significantly asymmetric, with the latter having a greater magnitude both in the event period and in the post-recommendation period. There are competing hypothesis on what drives the abnormal performance associated with these recommendations. The price pressure hypothesis predicts a temporary price effect to be reversed later due to buying/selling pressure by naive investors. The information hypothesis predicts a permanent price impact to reflect the information content provided by analysts' recommendations (Barber \& Loeffer, 1993). Stickel (1985) report that the initial price effect is permanent in response to a ranking change in Value Line, while Engelberg et al. (2012) document that the initial reaction is accompanied by a reversal for recommendations of Jim Cramer, host of the CNBC show Mad Money. Barber and Loeffler (1993) provide evidence of a partially mean-reverting price pattern, implying the existence of both effects.

Using either event-time portfolios (e.g., Stickel, 1995; Womack, 1996) or calendar time portfolios (e.g., Barber et al., 2001), researchers report that investors may be able to make excess returns, gross or net, by trading on publicly available information contained in analysts' recommendations, a result that is inconsistent with the semi-strong efficient market efficiency in Fama (1970). Nevertheless, some studies report that the speed of adjustment is very quick with information fully reflected in stock price in minutes (Kim et al., 1997) or even in seconds (Busse \& Green, 2002).

Womack (1996), among others, document post-recommendation drift for recommendation upgrades and downgrades. Researchers posits alternative explanations for this phenomenon. Loh (2010) attributes the under-reaction of investors' response to their inattention to the information contained in stock recommendations. Affleck-Graves and Mendenhall (1992) show that Value Line enigma is actually a reflection of post-earnings-announcement drift and the abnormal returns disappear after controlling for recent earnings surprises

The recent literature examines the impact of the posting of investment advice and recommendations disseminated through message boards, blogs, and social networking services on stock prices and market variables such as trading volumes and volatility. One main difference between social media outlets and traditional ones is that the former enable direct and immediate interaction among users (Chen et al., 2014). To quantify the information content or sentiment contained in user-generated texts, researcher often employ textual analysis. The predictive value of social media advice varies across different media platforms. Antweiler and Frank (2004) use machine learning algorithms to classify postings on Internet message boards at Yahoo! Finance and Raging Bull as bullish, bearish, or neutral. They report that bullish messages are associated with negative returns on the next day, although the effect is economically quite small. They also find that unusual message board activity predicts the presence of news stories in the traditional media Wall Street Journal. Using dictionary-based textual analysis, Tetlock (2007) document that the fraction of negative words extracted from a Wall Street Journal column (a proxy for negative sentiment) predicts an initial decline and subsequent reversal of Dow Jones index. Chen et al. (2014) provide evidence that advices and comments in Seeking Alpha website provide useful information for predicting investment returns. Using a sample of media coverage on TWSE listing firms, Wu and Lin (2017) report that the tone of news or announcements in media coverage has a price impact, though the extent of response varies for different type of investors. Kearney and Liu (2014) provide a review of textual analysis in finance.

Several prior studies have examined the determinants of cross-sectional abnormal returns. Stickel (1995) relate recommendation characteristics (the strength and magnitude of recommendation), brokerage house characteristics (marketing ability, analyst's reputation, size), and firm characteristics (firm size, earnings forecast revisions) to abnormal returns. Engelberg et al. (2012) find that the temporary initial price effect is strongest among small and illiquid stocks, which usually do not have rich information environment and are hard to arbitrage. Huang and Hus (2006) find that the abnormal returns are positively related to information asymmetry (firm age, years of listing) and prior-period returns, and negatively related to turnover and firm size for Taiwan 
stock market. Loh (2010) find that low-attention stocks react less to stock recommendations around the event window, but respond more in the subsequent drift, where turnover and institutional shareholding are considered to be alternative proxies for attention. The findings in Affleck-Graves and Mendenhall (1992) suggest that prior-period earnings may predict the magnitude of initial price impact of recommendations. Fama and French (1992) indicate that company size and price-to-book ratio might be important to explain abnormal returns. Amihud (2002) suggests that there is an illiquidity premium in average stock returns.

\section{Sample, Data, and Methodology}

This section describes the sample construction and introduces variables of interests for firm characteristics. We also briefly discuss the methodology used in this study.

\section{A. Stock Recommendation Data}

The sample of individual stock recommendation was hand-collected from various media outlets for the period from January to December in 2017. The stock recommendations from conventional media were selected from securities columns published in leading local newspapers, such as Commercial Times, Economic Daily News and United Daily News. We also collected recommendations from selected finance-related shows in News Channel and Business Channel of Unique Satellite Television (USTV) and the Finance Channel (currently, iNEWS Channel) of Sanlih Entertainment Television (SET). In these shows, such as "Money Line 100\%" in USTV, presenters invite financial pundits and investment analysts from securities investment consulting firms to provide investment analysis for their recommended stocks.

For recommendation from social media channel, we hand-collected stock recommendations posted on fan pages set up by analysts who share their investment opinions and provide stock recommendations in several popular social media platforms, such as Facebook.

\section{B. Stock Return Data and Financial Data}

To be included in the analysis, the sample firms have to meet some criteria. First, only common stocks of domestic listed companies on the TWSE and the Mainboard of TPEx were considered, and therefore we excluded preferred stocks, beneficial certificates, exchange-traded funds (ETF) and warrants. Secondly, the initial public offering (IPO) firms were excluded, because the hot issue and price stabilization operations may lead to unusual price fluctuation. Thirdly, to avoid the overlapping event windows for a particular firm, we require that a recommended firm to wait for at least 20 trading days after the event day before it can be eligible to be included in the sample again.

The stock return data come from the Taiwan Economic Journal (TEJ) Database. The stock return data include the daily returns of individual stocks and market indices, the Taiwan Stock Exchange Capitalization Weighted Stock Index (TAIEX) and Taipei Exchange Capitalization Weighted Stock Index (TPEX). Financial and accounting data to compute firm characteristics were also downloaded from TEJ database.

Our initial combined sample contains 573 stock recommendations, while three of them were dropped due to the unavailability of the corresponding financial data. The final combined sample contains 570 stock recommendations, with 277 and 293 observations disseminated through traditional media and social media, respectively. The combined sample recommendations are further classified into four groups by type of media (traditional/social) and type of exchange (TWSE/TPEx), with the number of observations ranging from 103 to 190. A detailed breakdown of the combined sample recommendations is presented in Table 1.

Table 1. Breakdown of Sample Recommendations

\begin{tabular}{|c|c|c|c|}
\hline \multicolumn{3}{|c|}{ Number of Recommendations for TWSE/TPEx Firms } & 573 \\
\hline \multicolumn{3}{|c|}{ Recommendations via Traditional Media with Missing Data } & 1 \\
\hline \multicolumn{3}{|c|}{ Number of Recommendations via Traditional Media } & 277 \\
\hline \multicolumn{3}{|c|}{ Recommendations via Social Media with Missing Data } & 2 \\
\hline \multicolumn{3}{|c|}{ Number of Recommendations via Social Media } & 293 \\
\hline Group & Initial Observations & Observations with Missing Data & Final Observations \\
\hline Traditional Media/TWSE & 162 & 0 & 162 \\
\hline Social Media/TWSE & 190 & 0 & 190 \\
\hline Traditional Media/TPEx & 116 & 1 & 115 \\
\hline Social Media/TPEx & 105 & 2 & 103 \\
\hline Total & 573 & 3 & 570 \\
\hline
\end{tabular}




\section{Quantile Regression}

As mentioned at the outset, the aim of this study is to examine the impact of various firm characteristics on the abnormal returns. Many prior studies use ordinary least-squares (OLS) regression to address the issue. While the OLS regression is useful to assess the impacts of explanatory variables on the average outcome of a response variable, there are cases that the impact of a regressor on the conditional distribution of the response variable may be different at points other than the mean. Specifically, we expect that the impact of firm characteristics for firms at high quantile levels, say 0.8 , of the conditional abnormal returns distribution may significantly differ from the impact for firms at low quantile levels. The results from quantile regressions should provide more relevant information to investors for making their decision regarding how to react to the release of a stock recommendation.

Koenker and Bassett (1978) developed the quantile regression model in which quantiles of the conditional distribution of the response variable are expressed as functions of observed repressors. In this paper, we estimate quantile regressions to explore whether firm characteristics will have the same impact on the conditional distribution of abnormal returns at different quantile levels.

Suppose the conditional quantile function at quantile $\tau$ for a response variable $\mathrm{y}$ is linear with a set of explanatory variables $\mathrm{x}$, namely $\mathrm{Q}_{\tau}(\mathrm{y} \mid \mathrm{x})=x^{\prime} \beta_{\tau}$, the quantile regression estimator $\hat{\beta}_{\tau}$ minimizes over $\beta_{\tau}$ of the objective function

$$
\mathrm{Q}\left(\beta_{\tau}\right)=\sum_{i: y_{i} \geq x_{i}^{\prime} \beta}^{N} \tau\left|y_{i}-x_{i}^{\prime} \beta_{\tau}\right|+\sum_{i: y_{i}<x_{i}^{\prime} \beta}^{N}(1-\tau)\left|y_{i}-x_{i}^{\prime} \beta_{\tau}\right|
$$

where $0<\tau<1$, and $\beta_{\tau}$ is a column vector of coefficients to be estimated. $y_{i}$ is the response variable and $x_{i}$ is a column vector of explanatory variables, with the subscript i referring to a specific observation. The objective function is a weighted sum of absolute deviations, where a weight of $\tau$ is assigned to positive deviations, and a weight of 1- $\tau$ is assigned to negative deviations. The subscript of $\beta_{\tau}$ is to reflect that the estimates of $\beta$ will change with the choices of $\tau$. For a more detailed discussion regarding the practical estimation issues, see Cameron and Trivedi (2010) for example. For an application of quantile regression in financial studies, see Huang, Liano, and Pan (2015) for example.

To examine the relation between the abnormal returns of stock recommendations and firm characteristics, we estimate the following regression at different quantile levels.

$$
\text { Return }_{i}^{\text {Abnormal }}=\beta_{0}+\beta_{1} \text { Cap }_{i}+\beta_{2} N P A T_{i}+\beta_{3} I N S_{i}+\beta_{4} \text { Shareholding }_{i}+\beta_{5} P / B_{i}+\beta_{6} \text { Turnover }_{i}+\varepsilon_{i}
$$

The response variable, abnormal Return, is the cumulative abnormal returns (CAR) computed over a [-20, 20] event window, where daily abnormal returns are the differences between actual returns and expected returns estimated from the market model. In this research, event date was $t=0$, that is, it was the date that the stock was recommended by traditional and social media. In order to understand the change of stock return before and after the event date, and to avoid the influence of other events by too long event period, therefore, 20 days before and after the event date were taken as event windows $(t=-20 \sim 20)$. In addition, to set up evaluation standard for abnormal return, it was needed to get the expected return of pre-event estimation period, in that period, it was not affected or interfered by special event, and it can facilitate reasonable expected return estimation. In this article, 200 days ( $\mathrm{t}=-220 \sim-21)$ before will be taken as estimation period. $R_{j t}$ is defined as the actual return of the $\mathrm{j}$-th security on the t-th day. $E\left(R_{j t}\right)$ is the expectation of $R_{j t} . R_{m t}$ is the market return. The expected return of event period is:

$$
E\left(R_{j t}\right)=R_{m t}
$$

The abnormal return is:

$$
A R_{j t}=R_{j t}-E\left(R_{j t}\right)
$$

Based on the results of prior studies, we choose some specific company characteristics as explanatory variables. These variables include firm size (-), prior-period profitability $(+)$, insider shareholding $(+)$, institutional shareholding (+), price-to-book ratio (-), and turnover (-), with the predicted sign shown in parenthesis.

Cap represents the market capitalization of the firm to serve as a proxy for size. NPAT is the after-tax profit margin of the firm, representing the prior-period earnings of the company. Shareholding denotes the percentage 
shareholding of insiders (board of directors and supervisors) to capture the information asymmetry between management and outside investors. INS represents institutional shareholding and is used to serve as a proxy for investors' attention. $\mathrm{P} / \mathrm{B}$ is the ratio of stock price over book value to capture the value effect. Turnover, as a proxy for liquidity, is the trading volume divided by the outstanding shares of the company. The summary statistics are listed in Table 2.

Table 2 . The summary statistics on company characteristics

\begin{tabular}{|c|c|c|c|c|c|c|}
\hline \multirow[b]{3}{*}{ mean } & \multicolumn{6}{|c|}{ Panel A : Traditional Media/TWSE } \\
\hline & $\begin{array}{c}\text { Cap } \\
\text { (NTD million) }\end{array}$ & NPAT (\%) & INS (\%) & $\begin{array}{c}\text { Shareholding } \\
(\%)\end{array}$ & $\begin{array}{l}\mathrm{P} / \mathrm{B} \\
(\%)\end{array}$ & $\begin{array}{c}\text { Turnover } \\
(\%)\end{array}$ \\
\hline & 24,531 & 20.08 & 30.72 & 52.04 & 13.25 & 9.71 \\
\hline stdev & 45,601 & 5.68 & 11.19 & 21.06 & 4.83 & 0.67 \\
\hline median & 4,340 & 18.99 & 28.45 & 48.50 & 11.98 & 9.53 \\
\hline minimum & 346 & 11.17 & 13.80 & 19.29 & 7.10 & 8.54 \\
\hline \multirow[t]{3}{*}{ maximum } & 259,304 & 32.07 & 54.69 & 99.45 & 26.74 & 11.41 \\
\hline & \multicolumn{6}{|c|}{ Panel B : Social Media/TWSE } \\
\hline & $\begin{array}{c}\text { Cap } \\
\text { (NTD million ) }\end{array}$ & NPAT (\%) & INS (\%) & $\begin{array}{c}\text { Shareholding } \\
(\%)\end{array}$ & $\begin{array}{l}\mathrm{P} / \mathrm{B} \\
(\%)\end{array}$ & $\begin{array}{c}\text { Turnover } \\
(\%)\end{array}$ \\
\hline mean & 12,060 & 9.39 & 23.38 & 3.33 & 2.02 & 1.02 \\
\hline stdev & 29,048 & 10.83 & 18.89 & 8.04 & 1.28 & 2.03 \\
\hline median & 3,180 & 7.65 & 18.70 & 0.12 & 1.69 & 0.39 \\
\hline minimum & 220 & -27.24 & 0 & 0 & 0.54 & 0.00 \\
\hline \multirow[t]{3}{*}{ maximum } & 198,303 & 85.71 & 98.65 & 94.53 & 8.44 & 40.84 \\
\hline & \multicolumn{6}{|c|}{ Panel C : Traditional Media/TPEx } \\
\hline & $\begin{array}{c}\text { Cap } \\
\text { (NTD million ) }\end{array}$ & NPAT (\%) & INS $(\%)$ & $\begin{array}{c}\text { Shareholding } \\
(\%)\end{array}$ & $\begin{array}{l}\mathrm{P} / \mathrm{B} \\
(\%)\end{array}$ & $\begin{array}{c}\text { Turnover } \\
(\%)\end{array}$ \\
\hline mean & 1,379 & 17.83 & 10.72 & 44.62 & 9.73 & 8.97 \\
\hline stdev & 1,595 & 5.07 & 5.19 & 19.56 & 2.79 & 0.37 \\
\hline median & 819 & 17.11 & 9.83 & 41.76 & 8.95 & 8.91 \\
\hline minimum & 74 & 11.12 & 4.68 & 16.63 & 6.41 & 7.87 \\
\hline \multirow[t]{3}{*}{ maximum } & 11,405 & 27.91 & 30.24 & 85.52 & 20.07 & 10.06 \\
\hline & \multicolumn{6}{|c|}{ Panel D : Social Media/TPEx } \\
\hline & $\begin{array}{c}\text { Cap } \\
\text { (NTD million ) }\end{array}$ & NPAT (\%) & INS (\%) & $\begin{array}{c}\text { Shareholding } \\
(\%)\end{array}$ & $\begin{array}{l}\mathrm{P} / \mathrm{B} \\
(\%)\end{array}$ & $\begin{array}{c}\text { Turnover } \\
(\%)\end{array}$ \\
\hline mean & 1,629 & 8.03 & 13.71 & 3.94 & 2.39 & 1.70 \\
\hline stdev & 2,217 & 9.48 & 11.53 & 8.77 & 1.45 & 3.01 \\
\hline median & 972 & 7.05 & 10.77 & 0.69 & 2.03 & 0.75 \\
\hline minimum & 171 & -35.07 & 0 & 0 & 0.71 & 0 \\
\hline maximum & 16,390 & 44.54 & 57.87 & 78.90 & 10.48 & 62.60 \\
\hline
\end{tabular}

\section{Empirical Results}

As discussed earlier, we aim to investigate the determinants of conditional distributions of cumulative abnormal returns (CAR) at different quantile levels. Based on the type of media and the type of exchange, we classified the combined sample firms into four samples. For each sample, we run four quantile regressions at quantile level of 
$0.2,0.4,0.6$, and 0.8 , respectively. We present the results of 16 quantile regressions in Table 3 to Table 6 . In general, the results indicate that the coefficient estimates on firm characteristics are not quite consistent in sign, magnitude, and significance for the four quantile levels in a given sample and across the four samples. The relation between firm characteristics and CAR tends to be more pronounced for TWSE firms than TPEx firms. For a given sample, firm characteristics only help to predict the abnormal returns for firms at higher CAR quantile level of 0.6 and 0.8 , and their relation become more notable the larger the quantile level.

We focus on the results of the quantile regressions at the 0.8 quantile in the following discussion. The well-documented size effect that firm size has a significantly negative effect on CAR is found only for the Social/TWSE sample in Table 4. This result is consistent with the OLS results in Huang and Hsu (2006). The shareholding of insiders has a positive and weak impact on CAR for TWSE firms, irrespective of the media type, as shown in in Table 3 and Table 4. This evidence is consistent with findings in Huang and Hsu (2006) that the larger the informational asymmetry the larger the market reaction to the release of a recommendation, provided that insiders' shareholding is a valid proxy for informational asymmetry. The coefficient on institutional shareholding (INS) is negative and weakly significant only for Traditional/TWSE firms, as shown in Table 3. This result is not consistent with the investor inattention explanation in Loh (2010) that the initial price effect is smaller for lower investors' attention, to the extent that institutional shareholding is a valid proxy for investors' attention. But this result may be consistent with the information environment explanation in Stickle (1995), if higher institutional shareholding implies a richer information environment and a smaller price impact of the released information. The coefficient on NPAT is positive and significant for the Traditional/TWSE sample and Social/TPEx sample, suggesting that higher prior-period earnings help to predict the abnormal returns. As indicated in Table 3 and Table 5, the coefficient on P/B is negative, as expected for the value effect, and significant at 0.6 and 0.8 quantiles for recommendations revealed through traditional media, regardless the exchange of listing. Turnover has a significantly positive effect for the Social/TWSE sample (consistent with the findings in Loh (2010) to the extent that Turnover is a valid proxy for investors' attention), while it has a significantly negative effect for the Social/TPEx firms (consistent with the evidence of Engelberg et al. (2012) and the prediction in Amihud (2002), to the extent that Turnover is a valid proxy for liquidity).

Table 3. Quantile Regression Estimates for the Traditional/TWSE Sample (Number of Observations=162)

\begin{tabular}{cccccccccccccccc}
\hline Quantile tau & \multicolumn{4}{c}{0.2} & \multicolumn{4}{c}{0.4} & \multicolumn{4}{c}{0.6} \\
\hline Variable & Coefficient & t-Statistic & Prob. & Coefficient & t-Statistic & Prob. & Coefficient & t-Statistic & Prob. & Coefficient t-Statistic & Prob. \\
\hline Constant & 3.3006 & 0.791 & 0.4301 & 7.4222 & 1.5712 & 0.1182 & 12.7903 & 2.4289 & 0.0163 & 15.206 & 2.7412 & 0.0068 \\
Capital & 0.1621 & 1.193 & 0.2347 & 0.0564 & 0.336 & 0.7373 & 0.0509 & 0.2592 & 0.7958 & -0.1128 & -1.0107 & 0.3138 \\
Shareholding & -0.1052 & -1.3554 & 0.1773 & -0.027 & -0.2574 & 0.7972 & 0.1023 & 0.7178 & 0.474 & 0.1519 & 1.6853 & $0.094^{*}$ \\
INS & -0.0627 & -0.2381 & 0.8121 & -0.1043 & -0.3043 & 0.7613 & -0.5349 & -1.4015 & 0.1631 & -0.6238 & -3.4013 & $0.0009^{* * *}$ \\
NPAT & 0.0521 & 0.2144 & 0.8305 & 0.1288 & 0.3952 & 0.6932 & 0.5361 & 1.4393 & 0.1521 & 0.9087 & 3.2197 & $0.0016^{* *}$ \\
P/B & 0.0047 & 0.0751 & 0.9402 & -0.052 & -0.679 & 0.4981 & -0.167 & -1.8903 & $0.0606^{*}$ & -0.2998 & -3.5633 & $0.0005^{* * *}$ \\
Turnover & -0.3509 & -0.7626 & 0.4469 & -0.5695 & -1.1062 & 0.2703 & -0.9449 & -1.6905 & $0.0929^{*}$ & -0.8599 & -1.4349 & 0.1533 \\
\hline
\end{tabular}

Note: $* * *$ and $* * *$ indicate statistical significance level at $10 \%, 5 \%$ and $1 \%$, respectively

Table 4. Quantile Regression Estimates for the Social/TWSE Sample (Number of Observations=190)

\begin{tabular}{cccccccccccccccc}
\hline Quantile tau & \multicolumn{3}{c}{0.2} & \multicolumn{1}{c}{0.4} & \multicolumn{4}{c}{0.6} \\
\hline Variable & Coefficient & t-Statistic & Prob. & \multicolumn{1}{c}{ Coefficient t-Statistic } & Prob. & Coefficient t-Statistic & Prob. & Coefficient t-Statistic & Prob. \\
\hline Constant & 0.5132 & 0.1109 & 0.9118 & 5.7877 & 1.1929 & 0.2344 & 9.0647 & 1.8127 & 0.0715 & 10.5231 & 2.4864 & 0.0138 \\
Capital & -0.2127 & -0.4358 & 0.6635 & -0.7057 & -1.4037 & 0.1621 & -0.959 & -1.8155 & $0.0711^{*}$ & -0.9175 & -2.1181 & $0.0355^{* *}$ \\
Shareholding & 0.0023 & 0.2797 & 0.78 & 0.0091 & 0.9235 & 0.3569 & 0.0078 & 0.6281 & 0.5307 & 0.02 & 1.7994 & $0.0736^{*}$ \\
INS & 0.0099 & 0.5672 & 0.5713 & 0.0207 & 1.1895 & 0.2358 & 0.0038 & 0.2005 & 0.8413 & -0.0271 & -1.3348 & 0.1836 \\
NPAT & 0.0221 & 1.8659 & $0.0637^{*}$ & 0.0168 & 1.0994 & 0.273 & 0.0271 & 1.2152 & 0.2258 & 0.0308 & 1.0781 & 0.2824 \\
P/B & 0.0726 & 0.3875 & 0.6988 & -0.1931 & -1.0424 & 0.2986 & -0.0423 & -0.2023 & 0.8399 & -0.116 & -0.5111 & 0.6099 \\
Turnover & -0.2367 & -1.3342 & 0.1838 & 0.4016 & 0.7431 & 0.4584 & 1.0187 & 3.0564 & $0.0026^{* *}$ & 1.4476 & 2.625 & $0.0094^{* *}$ \\
\hline
\end{tabular}

Note: $* * *$ and $* * *$ indicate statistical significance level at $10 \%, 5 \%$ and $1 \%$, respectively

Statistical significance at the $10 \%, 5 \%$ and $1 \%$ levels are denoted by $*, * *$ and $* * *$, respectively. 
Table 5. Quantile Regression Estimates for the Traditional/TPEx Sample (Number of Observations=115)

\begin{tabular}{ccccccccccccccc}
\hline Quantile tau & \multicolumn{4}{c}{0.2} & \multicolumn{1}{c}{0.4} & \multicolumn{4}{c}{0.6} & \multicolumn{4}{c}{0.8} \\
\hline Variable & Coefficient & t-Statistic & Prob. & Coefficient & t-Statistic & Prob. & Coefficient & t-Statistic & Prob. & Coefficient & t-Statistic & Prob. \\
\hline Constant & -2.5312 & -0.3308 & 0.7415 & 6.2366 & 0.6966 & 0.4875 & 7.9988 & 0.6988 & 0.4862 & 33.5115 & 2.2499 & 0.0265 \\
Capital & -0.3268 & -0.612 & 0.5418 & 0.2097 & 0.3131 & 0.7548 & 0.1371 & 0.1953 & 0.8455 & 0.1678 & 0.4094 & 0.683 \\
Shareholding & 0.0313 & 0.1361 & 0.892 & -0.058 & -0.2048 & 0.8381 & 0.0208 & 0.0896 & 0.9287 & -0.0698 & -0.4817 & 0.631 \\
INS & 0.3241 & 0.5288 & 0.598 & 0.8653 & 0.77 & 0.443 & 0.9374 & 0.6027 & 0.548 & -1.3026 & -0.9762 & 0.3312 \\
NPAT & 0.2968 & 0.252 & 0.8015 & -1.992 & -0.9763 & 0.3311 & -2.2829 & -0.9475 & 0.3455 & 2.3625 & 0.9922 & 0.3233 \\
P/B & -0.1238 & -0.7258 & 0.4695 & -0.151 & -0.8667 & 0.388 & -0.341 & -2.1179 & $0.0365^{* *}$ & -0.3158 & -1.8377 & $0.0689 *$ \\
Turnover & 0.0241 & 0.0253 & 0.9798 & 0.5451 & 0.3368 & 0.737 & 0.9177 & 0.4567 & 0.6488 & -3.8562 & -1.7417 & $0.0844 *$ \\
\hline
\end{tabular}

Note: $* * *$ and $* * *$ indicate statistical significance level at $10 \%, 5 \%$ and $1 \%$, respectively

Table 6. Quantile Regression Estimates for Social/TPEx Sample (Number of Observations=103)

\begin{tabular}{ccccccccccccccc}
\hline Quantile tau & \multicolumn{4}{c}{0.2} & \multicolumn{4}{c}{0.4} & \multicolumn{4}{c}{0.6} \\
\hline Variable & Coefficient & t-Statistic & Prob. & Coefficient & t-Statistic & Prob. & Coefficient & t-Statistic & Prob. & Coefficient t-Statistic & Prob. \\
\hline Constant & 8.4891 & 0.6135 & 0.541 & 9.6774 & 0.6766 & 0.5003 & 11.6956 & 0.8078 & 0.4212 & -0.0248 & -0.0018 & 0.9985 \\
Capital & -1.2268 & -0.7747 & 0.4404 & -1.2475 & -0.7581 & 0.4502 & -1.2707 & -0.7953 & 0.4284 & 0.5992 & 0.3973 & 0.692 \\
Shareholding & 0.0066 & 0.3025 & 0.763 & -0.0038 & -0.1629 & 0.8709 & 0.0173 & 0.6276 & 0.5317 & 0.0067 & 0.2219 & 0.8249 \\
INS & 0.0803 & 1.572 & 0.1192 & 0.0836 & 1.4832 & 0.1413 & 0.0678 & 0.9317 & 0.3538 & -0.0796 & -1.0359 & 0.3029 \\
NPAT & -0.0006 & -0.2606 & 0.795 & -0.0004 & -0.1407 & 0.8884 & 0.002 & 0.7636 & 0.447 & 0.0056 & 2.4834 & $0.0147 * *$ \\
P/B & 0.001 & 0.0029 & 0.9977 & -0.1871 & -0.4837 & 0.6297 & -0.3255 & -0.8835 & 0.3792 & -0.1038 & -0.4284 & 0.6693 \\
Turnover & -0.3115 & -0.6653 & 0.5074 & 0.5196 & 1.1336 & 0.2598 & 0.5324 & 1.2514 & 0.2138 & -0.0323 & -0.0593 & 0.9528 \\
\hline
\end{tabular}

Note: $* * *$ and $* * *$ indicate statistical significance level at $10 \%, 5 \%$ and $1 \%$, respectively

\section{Conclusions}

In this study, we examine the determinants of the stock performance of analysts' recommendations for companies listed in Taiwan stock markets using quantile regression model. The sample of individual stock recommendations is hand-collected from several media outlets from January to December in 2017. We classify the combined recommendations into four samples by media type and exchange type. We measure cumulative abnormal returns using the market model of event study and run quantile regressions at four selected quantile levels.

Our findings show that the cross-sectional relation between firm characteristics and cumulative abnormal returns is not homogeneous across various quantiles of abnormal returns. Furthermore, our results show that the impact of firm characteristics is conditional on the type of media and the type of market structure. Specifically, our evidence indicate that the relation tends to be significant for firms at higher performance quantile levels and tends to be more pronounced for TWSE firms than TPEx firms. The impact of the determinants on abnormal returns tend to be more significant for the Traditional/TWSE sample, where larger insider shareholding, higher prior-period earnings, smaller institutional shareholding, and lower price-to-book help to predict larger abnormal returns for firms in the highest abnormal performance quantile. The well-documented negative size effect in prior studies is found only for the Social/TWSE sample.

Our results complement the extant studies that use the OLS method to examine the impact of firm characteristics on the price response to analysts' recommendation. Our findings also have practical implications for investors, as they may be able to enhance their investment performance by taking into consideration the relevant determinants when they make the decision whether to follow an analyst's recommendation.

\section{References}

Affleck-Graves, J., \& Mendenhall, R. R. (1992). The Relation between the Value Line Enigma and Post-Earnings-Announcement Drift. Journal of Financial Economics, 31(1), 75-96. https://doi.org/10.1016/0304-405X(92)90012-M

Amihud, Y. (2002). Illiquidity and Stock Returns: Cross-Section and Time-Series Effects. Journal of Financial Markets, 5, 31-56. https://doi.org/10.1016/S1386-4181(01)00024-6 
Antweiler, W., \& Frank, M. Z. (2004). Is All That Talk Just Noise? The Information Content of Internet Stock $\begin{array}{lllll}\text { Message Boards. Journal of } & \text { 1259-1294. }\end{array}$ https://doi.org/10.1111/j.1540-6261.2004.00662.x

Barber, B, Lehavy, R., \& Trueman, B. (2010). Ratings Changes, Ratings Levels, and the Predictive Value of $\begin{array}{llll}\text { Analysts' Recommendations. } \quad \text { Financial } & \text { Management, }\end{array}$ https://doi.org/10.1111/j.1755-053X.2010.01083.x

Barber, B., Lehavy, R., McNichols, M., \& Trueman, B. (2001). Can Investor Profit from the Prophets? Security Analyst Recommendations and Stock Returns. Journal of Finance, 56(2), 531-563. https://doi.org/10.1111/0022-1082.00336

Barber, B. M., \& Loeffler, D. (1993). The "Dartboard" Column: Second-Hand Information and Price Pressure. Journal of Financial and Quantitative Analysis, 28(2), 273-284. https://doi.org/10.2307/2331290

Busse, J. A., \& Green, C., (2002). Market Efficiency in Real Time. Journal of Financial Economics, 65(3), 415-437. https://doi.org/10.1016/S0304-405X(02)00148-4

Cameron, A. C., \& Trivedi, P. K. (2010). Microeconometrics Using Stata, College Station, Texas, StataCorp LP. https://doi.org/10.1111/1475-4932.12006

Chang, Y. H., \& Chan, C. C. (2008). Financial Analysts' Stock Recommendation Revisions and Stock Price Changes. Applied Financial Economics, 18(4), 309-325. https://doi.org/10.1080/09603100600606131

Chen, H., De, P., Hu, Y., \& Hwang, B. (2014). Wisdom of Crowds: The Value of Stock Opinions Transmitted Through Social Media. The Review of Financial Studies, 27(5), 1367-1403. https://doi.org/10.1093/rfs/hhu001

Chiao, C. S., Lin, T. Y., \& Lee, C. F. (2017). The Reactions to On-Air Stock Reports: Prices, Volume, and Order $\begin{array}{llll}\text { Submission } \quad \text { Behavior. Pacific-Basin } & \text { Finance }\end{array}$ https://doi.org/10.1016/j.pacfin.2017.05.004

Copeland, T. E., \& Mayers, D. (1982). The Value Line Enigma (1965-1978): A Case Study of Performance Evaluation Issues. Journal of Financial Economics, 10, 289-322. https://doi.org/10.1016/0304-405X(82)90004-6

Desai, H., \& Jain, P. C. (1995). An Analysis of the Recommendations of the "Superstar" Money Managers at Barron's Annual Roundtable. Journal of Finance, 50(4), 1257-1273. https://doi.org/10.1111/j.1540-6261.1995.tb04057.x

Engelberg, J., Sasseville, C., \& Williams, J. (2012). Market Madness? The Case of Mad Money. Journal of Management Science, 58(2), 351-364. https://doi.org/10.1287/mnsc. 1100.1290

Fama, E., \& French, K. R. (1992). The Cross-Section of Expected Stock Returns. Journal of Finance, 47, 427-465. https://doi.org/10.1111/j.1540-6261.1992.tb04398.x

Fama, E. (1970). Efficient Capital Markets: A Review of Theory and Empirical Work. Journal of Finance, 25 , 383-417. https://doi.org/10.1111/j.1540-6261.1970.tb00518.x

Huang, G. C., Liano, K., \& Pan, M. S. (2015). Investor Opinion Divergence and Post-Repurchase Announcement Stock Price Drift. Applied Economics, 47(22), 2293-2306. https://doi.org/10.1080/00036846.2015.1005823

Huang, H. H., \& Hsu, H. T. (2006). Can Investors Profit from the Recommendations of Brokerage Firms? Review of Securities \& Futures Markets, 18, 79-115. https://dx.doi.org/10.6529/RSFM.2006.18(2).3

Huth, W., \& Maris, B. (1992). Large and small firm stock price response to 'Heard on The Street' recommendation. Journal of Accounting, Auditing \& Finance, 7(1), 27-44. https://doi.org/10.1177/0148558X9200700103

Kearney, C., \& Liu, S. (2014). Textual Sentiment in Finance: A Survey of Methods and Models. International Review of Financial Analysis, 33, 171-185. https://doi.org/10.2139/ssrn.2213801

Kim, S. T., Lin, J. C., \& Slovin, M. B. (1997). Market Structure, Informed Trading, and Analysts' Recommendation. Journal of Financial and Quantitative Analysis, 32(4), 507-524. https://dx.doi.org/10.1016/j.jebo.2011.10.012

Koenker, R., \& Bassett, G. (1978). Regression Quantiles. Econometrica, 46, 33-50. https://doi.org/10.2307/1913643 
Li, Q., Wang, T., Li, P., Liu, L., Gong, Q., \& Chen, Y. (2014). The Effect of News and Public Mood on Stock Movements. Information Sciences, 278, 826-840. https://dx.doi.org/10.1016/j.ins.2014.03.096

Liu, P., Smith, S. D., \& Syed, A. A. (1990). Stock Price Reactions to the Wall Street Journal's Securities Recommendations. Journal of Financial and Quantitative Analysis, 25, 399-410. https://dx.doi.org/10.2307/2330704

Loh, R. K. (2010). Investor Inattention and the Under reaction to Stock Recommendations. Financial Management, 39(3), 1223-1252. https://doi.org/10.1111/j.1755-053X.2010.01110.x

Michaely, R., \& Womack, K. L. (2005). Market Efficiency and Biases in Brokerage Recommendations, In R. H. Thaler (Ed.), Advances in Behavioral Finance II. Princeton, NJ: Princeton University Press. Retrieved from https://www.researchgate.net/publication/243627158_Advances_in_Behavioral_Finance_II

Stickel, S. E. (1985). The Effect of Value Line Investment Survey Rank Changes on Common Stock Prices. Journal of Financial Economics, 14(1), 121-143. https://doi.org/10.1016/0304-405X(85)90046-7

Stickel, S. E. (1995). The Anatomy of the Performance of Buy and Sell Recommendations. Financial Analysts Journal, 51, 25-39. https://doi.org/10.2469/faj.v51.n5.1933

Tetlock, P. C. (2007). Giving Content to Investor Sentiment: The Role of Media in the Stock Market. Journal of Finance, 62(3), 1139-1168. https://doi.org/10.1111/j.1540-6261.2007.01232.x

Tetlock, P. C. (2015). The Role of Media in Finance, In S. P. Anderson, J. Waldfogel, \& D. Strömberg (Eds.), Handbook of Media Economics I. Amsterdam, Netherlands: North-Holland. Retrieved from https://www.sciencedirect.com/science/article/pii/B9780444627216100009?via\%3Dihub

Tetlock, P. C., Saar-Tsechansky, M., \& Macskassy, S. (2008). More Than Words: Quantifying Language to Measure Firms' Fundamentals. Journal of Finance, 63(3), 1437-1467. https://doi.org/10.1111/j.1540-6261.2008.01362.x

Womack, K. L. (1996). Do Brokerage Analysts' Recommendations Have Investment Value? Journal of Finance, 51(1), 137-167. https://doi.org/10.1111/j.1540-6261.1996.tb05205.x

Wu, C. H., \& Lin, C. J. (2017). The Impact of Media Coverage on Investor Trading Behavior and Stock Returns. Pacific-Basin Finance Journal, 43, 151-172. https://doi.org/10.1016/j.pacfin.2017.04.001

Yu, Y., Duan, W., \& Cao, Q. (2013). The Impact of Social and Conventional Media on Firm Equity Value: A Sentiment Analysis Approach. Decision Support Systems, 55(4), 919-926. https://doi.org/10.1016/j.dss.2012.12.028

\section{Copyrights}

Copyright for this article is retained by the author(s), with first publication rights granted to the journal.

This is an open-access article distributed under the terms and conditions of the Creative Commons Attribution license (http://creativecommons.org/licenses/by/4.0/). 